\title{
Cardiac arrest associated with hypokalaemia in a patient receiving mithramycin
}

\author{
Y. Bashir ${ }^{1}$ and C.R.V. Tomson ${ }^{2}$ \\ ${ }^{1}$ Department of Neurology, General Hospital, Newcastle on Tyne and ${ }^{2}$ Home Dialysis Office, Royal Victoria \\ Infirmary, Newcastle on Tyne NE1 4LP, UK.
}

\begin{abstract}
Summary: The case is reported of a patient who developed severe hypokalaemia, leading to cardiac arrest, while receiving mithramycin for painful Paget's disease. The patient was also receiving antihypertensive and anti-anginal treatment including bendrofluazide, but plasma potassium before the administration of mithramycin was normal. Hypokalaemia has been reported in previous studies of the use of mithramycin but has received little attention. The drug should be used with great care in patients with cardiovascular disease and in those receiving diuretics.
\end{abstract}

\section{Introduction}

The efficacy of mithramycin in the treatment of painful Paget's disease was first reported in $1969,{ }^{1}$ and despite the development of newer agents the drug still has a role in the management of severe pain and in the differential diagnosis of pain in Paget's disease complicated by osteoarthritis. ${ }^{2}$ Much attention has been paid to its effects on calcium metabolism, and the haematological side effects are also well documented. Hypokalaemia is much less well recognized. In their report of the first 15 patients treated with mithramycin ${ }^{3}$ the authors mentioned potassium depletion and mild renal impairment in one patient taking hydrochlorothiazide and recommended that diuretics and other potentially nephrotoxic drugs be withheld during treatment with mithramycin. Elias and Evans reported that plasma potassium was unchanged 48 hours after infusion ${ }^{4}$ but did not perform interim measurements. Fillastre et al. ${ }^{5}$ recorded statistically significant reductions in plasma potassium of the order of $0.5 \mathrm{mmol} / 1$ in a group of patients with malignant disease receiving mithramycin $25 \mu \mathrm{g} / \mathrm{kg}$. The fall occurred within the first two hours of the infusion and was not associated with any detectable increase in urinary potassium excretion. The authors did not speculate about the mechanism involved but intracellular redistribution of potassium ions similar to that caused by alkalosis and adrenaline seems possible. We report a case in which the development of

Correspondence: C.R.V. Tomson, M.R.C.P.

Accepted: 17 September 1987 severe hypokalaemia following mithramycin administration was associated with cardiac arrest.

\section{Case report}

A 76 year old woman with active Paget's disease: affecting the left tibia was admitted for mithramycin therapy. She had a history of essential hypertension and angina pectoris and was taking bendrofluazide $10 \mathrm{mg} /$ day as well as atenolol, nifedipine, and isosorbide dinitrate. Baseline electrolytes were normal including plasma potassium $3.8 \mathrm{mmol} / 1$. She was treated with daily intravenous infusions of mithramycin $(15 \mu \mathrm{g} / \mathrm{kg}$ in $500 \mathrm{ml}$ of $5 \%$ dextrose) over 6 hours. The first two infusions proceeded uneventfully and interim measurements of plasma potassium were 3.7 and $3.6 \mathrm{mmol} / \mathrm{l}$. Two hours after completing the third dose she suddenly collapsed and was pulseless and apnoeic for 60 seconds before restoration of an output following a praecordial blow. By the time that monitoring equipment was available she was in sinus rhythm and had regained consciousness. There was no evidence of myocardial infarction on serial electrocardiograms or cardiac enzymes but the plasma potassium at the time of the collapse was $2.0 \mathrm{mmol} / 1$. She had not experienced any vomiting or diarrhoea and no drugs or bicarbonate were given at the arrest. She was treated with intravenous potassium supplements and serial measurements of plasma potassium showed a slow return to normal. No further arrhythmias were

(C) The Fellowship of Postgraduate Medicine, 1988 
detected. By the next day plasma potassium had risen to $4.9 \mathrm{mmol} / 1$ and supplements were stopped. She remained normokalaemic through the remainder of her admission.

\section{Discussion}

There are no published reports of severe or clinically significant hypokalaemia attributed to mithramycin, and neither the Committee on Safety of Medicines nor the manufacturers are aware of any such cases. In the present case the close temporal association between mithramycin therapy and the development of hypokalaemia without alternative cause is suggestive of a causal relationship, although it is difficult to account for the normal plasma potassium levels recorded after the first two doses. However, these samples were drawn 8-10 hours after completion of the preceding infusion; if we hypothesize that hypokalaemia following mithramycin is due to temporary redistribution within cells, re-equilibration may have occurred within this time. Concurrent treatment with a thiazide diuretic may have potentiated this redistribution of potassium, leading to the severe hypokalaemia observed.

\section{References}

1. Ryan, W.G., Schwartz, T.B. \& Perlia, C.P. Effects of mithramycin on Paget's disease of bone. Ann Intern Med 1969, 70: 549-557.

2. Heath, D.A. The role of mithramycin in the management of Paget's disease. Metab Bone Dis Relat Res 1981, 4 \& 5: 343-345.

3. Ryan, W.G., Schwartz, T.B. \& Northrop, G. Experiences in the treatment of Paget's disease of bone with mithramycin. $J A M A$ 1970, 213: 1153-1157.

4. Elias, E.G. \& Evans, J.T. Mithramycin in the treatment of Paget's disease of bone. J Bone Joint Surg (Am) 1972, 54: 1730-1736.
The relationship between hypokalaemia and cardiac arrhythmias remains controversial. In the setting of acute myocardial infarction it is widely accepted that hypokalaemia is associated with high risk of ventricular arrhythmias. However, hypokalaemia in this situation may simply be a marker of very high catecholamine levels ${ }^{6}$ and it is less clear whether hypokalaemia from other causes is also associated with an increased risk of arrhythmias. Although we would hesitate to draw conclusions from a single case, we feel that acute drug-induced hypokalaemia leading to ventricular fibrillation is likely to have been responsible for our patient's collapse. Our experience suggests that careful attention should be paid to monitoring and correction of plasma potassium when mithramycin is being administered, particularly to patients with pre-existing cardiovascular disease or to those receiving diuretics.

\section{Acknowledgements}

The authors thank Dr F. Clark, Consultant Physician, Freeman Hospital, Newcastle upon Tyne, for his permission to report this case.

5. Fillastre, J.P., Maitrot, J., Lannone, M.A. et al. Renal function and alterations in plasma electrolyte levels in normocalcaemic and hypercalcaemic patients with malignant diseases given intravenous infusion of mithramycin. Chemotherapy 1974, 20: 280-295.

6. Morgan, D.B. \& Young, R.M. Acute transient hypokalaemia: new interpretation of a common event. Lancet 1982, ii: 751-752. 